\title{
Key factors affecting the diversity of Sphagnum cover inhabitants with the focus on ground beetle assemblages in Central-Eastern European peat bogs
}

\author{
G. Sushko \\ Department of Ecology and Environmental Protection, Vitebsk State University P. M. Masherov, Moskovski Ave. 33, \\ 21008 Vitebsk, Belarus. E-mail: gennadisu@tut.by
}

Keywords: Belarus, Carabidae, diversity, environmental factors, Sphagnum dwellers.

\begin{abstract}
A key structural component in peat bog formation is Sphagnum spp., which determines very specific associated environmental conditions. The aim of this study was to characterise some of the key factors affecting the diversity, species richness and abundance of sphagnum inhabiting ground beetles and to examine the maintenance of stable populations of cold adapted specialised peat bog species. A total of 52 carabid species were recorded by pitfall traps along six main habitats, such as the lagg zone, pine bog, hollows, hummock open bog and dome. The results are characterised by a low diversity, which vary significantly among habitat types, and include a high abundance of a few carabid species. Among the variables influencing carabid species richness and abundance were plant cover, $\mathrm{pH}$ and the conductivity of the Sphagnum mat water. Vascular plant cover was a key factor shaping carabid beetle assemblages in the slope and the dome, while electric conductivity affected carabid beetle assemblage in the lagg. Whereas, the water level was the most important factor for the hollows. At the same time, peat bog specialists showed low sensitivity to the gradient of the analysed variables. Most of the specialised species are protected boreal beetles in the temperate zone of Europe, and therefore Belarusian peat bogs are a significant repository of cold adapted specialised bog species and potentially represent a significant refugia for these species in the context of global warming.
\end{abstract}

Abbreviations: ANOVA-Analysis of variance, CCA-Canonical Correspondence Analysis, D-Dome; GLM-Generalized Linear Models, HOL-Hollows, HUM-Hummocks, LZ-Lagg Zone, OBS-Open Bog, PB-Pine Bog, PCA-Principal Component Analysis.

Nomenclature for carabids: Hůrka (1996), Freude et al. (2004).

\section{Introduction}

Belarus, located in the geographic centre of Europe and with a substantial cover of wetland, is one of Europe's key peatland countries (Bambalov and Rakovich 2005). More than $50 \%$ of ancient large Belarusian peat bogs are preserved in a relatively natural condition. The area of many of these peatlands may exceed several thousand hectares (Bragg et al. 2003, Bambalov and Rakovich 2005). By way of contrast, in Western Europe, many countries have lost more than $90 \%$ of their peatland heritage (Bragg et al. 2003), and further losses of peatlands and related wetland habitats are projected for some regions (Coll et al 2014, 2016). Being among the most threatened habitats, peat bogs have a relatively rare occurence in most countries of Central Europe as a consequence of historical and recent disturbances and contemporary pressures. Therefore, almost intact Belarusian peatlands are suitable as model objects for studying ecological trends associated with peat bog ecosystems, whereas in most other countries this is not possible.

Sphagnum is a key structural component in peat bog formation, and hence a fundamental part of what makes peatland systems very different from other ecosystems. Key features of Sphagnum that shape the habitat and drive peatland dynamics include; (1) they create an environment that is acidic, nutrient poor, wet, and anoxic, (2) they are resistant to decay, and (3) there are a number of species that specialise in different parts of mire gradients (e.g., water level, $\mathrm{pH}$, and shading) (Wieder et al. 2006, Rydin and Jeglum 2006). Where Sphagnum grows it commonly completely covers the ground, either by itself or in association with other bryophyte species, and can also closely co-occur with a number of vascular plants (such as sedges and dwarf shrubs). The formation of peat bog structures may in many cases be dependent upon these interactions between Sphagnum and vascular plants. Several important aspects for Sphagnum dwelling invertebrates can be related to aspects of this cover (Wieder et al. 2006, Rydin and Jeglum 2006). Most of the biological diversity of peat bogs is associated with these resident invertebrate assemblages, and those invertebrates are the primary trophic links between plants and vertebrates (Rydin and Jeglum 2006, Spitzer and Danks 2006, Sushko 2016a,b). Local mesoclimates and microclimates, and their associated ecological niches, are conspicuously constant in these habitats, and together with small-scale dynamics support the long-term ecological constancy associated with the whole bog ecosystem (Spitzer and Danks 2006). Thus, water level, $\mathrm{pH}$, mineral content and microclimate may be the main abiotic factors affecting Sphagnum carpet inhabitant diversity.

Chemical deficiencies almost entirely exclude, for example, lumbricid worms, and snails from acidic bogs (Peus 1928, Rydin and Jeglum 2006, Spitzer and Danks 2006), and low nutrient availability may exclude animal species that 
have high nutrient demands. While these claims of species poorness are largely correct for several taxonomic and functional groups of animals. Main invertebrate inhabitants associated with moss cover include spiders, ants and beetles, among which ground beetles (Coleoptera: Carabidae) are the dominant component (Peus 1928, Maavara 1957, Spitzer et al. 1999, Mossakowski et al. 2003, Dapkus and Tamutis 2008, Spungis 2008).

Therefore, carabid beetle assemblages of peat bogs represent ideal model organisms to explore biodiversity patterns and the metacommunity ecology associated with these wetland habitats (Spitzer et al. 1999, Mossakowski et al. 2003). In addition, the study of the environmental variables driving such biodiversity patterns is essential in establishing proper guidelines for the conservation of the fauna of bogs.

Invertebrate communities in Sphagnum-dominated peatlands are sufficiently well documented (Främbs et al. 2002, Mossakowski et al. 2003, Dapkus and Tamutis 2008). However, much less is known about their relationships to environmental parameters and responses to ecological gradients, especially in large nearly intact peat bogs, which almost did not remain in Europe.

The working hypothesis formulated was that the carabid assemblage composition would vary in gradient between the Sphagnum habitats, and that among the main variables likely to limit ground beetle diversity are abiotic controlling factors. The aim of this study was to characterise some of the key factors affecting the diversity, species richness and abundance of Sphagnum-inhabiting ground beetles and those which support the maintenance of stable populations of cold adapted specialised peat bog species.

\section{Methods}

\section{Study site}

The study was conducted in Belarusian Lake District $\left(55^{\circ} 34^{\prime}-55^{\circ} 37^{\prime} \mathrm{N} ; 27^{\circ} 55^{\prime}-28^{\circ} 06^{\prime} \mathrm{E}\right)$ in the largest and pristine peatlands in Central-Eastern Europe «Moch» (4602 hectare) and «Yelnia» (19984 hectare). Peat bog surfaces are typically convex as a result of the factors controlling their formation; thus there are plateau located at the edges of the border zone (lagg zone), a slope, and a peak. Six main habitats were selected to represent a peat bog gradient; lagg (3050 meters from the border of the peat bogs), pine bog, hollows, hummocks, open bog (on the slope), and dome (on the peak, which can have a height of 3 to 7 meters, depending on the peat layer thickness). These micro-habitats within the bog complex differ in their vegetation cover, plant species composition, bog water level, mineral content (conductivity), and $\mathrm{pH}$ (Tables S1, S2). Thirty-six study sites in these peat bog habitats were selected.

\section{Environmental variables}

To characterise the peat bog habitats, five variables (mean values $\pm \mathrm{SE}$ ), that represent important environmental condi- tions for Sphagnum layer inhabitants. The environmental data recorded included; in situ $\mathrm{pH}$ using a $\mathrm{pH}$ meter (model HI 8314), electrical conductivity of Sphagnum mat water at a depth of 3-5 cm using a Multi-range Conductivity Meter (model HI 9033), light level using a Digital Light Meter (model MS 6610). Sphagnum mat water level was established using a plastic pipe with holes with a diameter of $50 \mathrm{~mm}$, a wall thickness of $1.8 \mathrm{~mm}$ and a length of $1500 \mathrm{~mm}$ in which the water level was measured. These were measured at 10-14 day intervals at each site. Vegetation parameters were recorded according to Brown (1954). The vascular plant cover (\%) and plant height $(\mathrm{cm})$ were examined in June and September. In each site, shrub and herb species were recorded in three randomly selected $1 \mathrm{~m}^{2}$ plots (Table $\mathrm{S} 2$ ).

\section{Ground beetle survey}

For the collection of ground beetles, pitfall traps in the form plastic cups $\left(250 \mathrm{~cm}^{3}\right)$ with a preservative liquid $(4 \%$ formaldehyde solution) in each site were used. To reduce the probability of spatial autocorrelation among the habitats I established $300 \mathrm{~m}$ as a minimum acceptable distance among them. Three sampling sites ( $50 \mathrm{~m}$ apart from each other) were placed in each of the 6 habitats of two studied peat bogs. Each site consisted of 10 traps placed $2 \mathrm{~m}$ apart (i.e. 10 traps per site, 30 traps per habitat, and 360 traps it total). The study was conducted in the period of $2015-2017$. The traps were checked and beetles collected at 10-14 day intervals. Pitfall trapping was started in the first half of April and all traps were removed at the beginning of November in each of the years.

Ground beetle species were identified according to Hůrka (1996) and Freude et al. (2004). Voucher specimens were deposited in the Zoological Museum of Vitebsk State University.

Habitat preferences of carabid beetles follow Aleksandrowicz (2014) and Information System about Beetles of Poland (Coleoptera Poloniae 2017).

\section{Data analyses}

All data from each of the six site types of two peat bogs were summed to obtain one value per habitat. To estimate the potential number of species, the estimators Chao 1 and Jackknife 1 were used. These widely applied nonparametric estimators are reliable when calculating a minimum species richness in the analysis of biodiversity (Chao 1987, Magurran 2004). The estimators were calculated using the software SPADE (Chao et al. 2015).

To examine the carabid alpha diversity, Shannon (H') index was applied. The index was calculated using the software Past (Hammer et al. 2001).

Differences of environment parameters, ground beetle species richness, abundances and Shannon diversity were examined using Kruskal-Wallis H test with Dunn's post hoc test with Bonferroni correction and with analysis of variance (ANOVA) using Tukey HSD permutation tests (the level of significance $\mathrm{P}<0.05$ ) (Siegel and Castellan 1988). The en- 
vironment parameter mean values and ground beetle assemblage mean abundances were log transformed. Prior to analyses, the data were tested for normality using Shapiro-Wilk normality test. Possible intercorrelations of all environment variables were examined by Spearman rank-correlation (rs > $0.7)$.

Generalized Linear Models (GLM) with a Poisson distribution was used to analyse the effects of the measured habitat parameters on the diversity, species richness and numbers of carabids. Percent data of environmental variables were arcsine transformed. Collinearity in the explanatory variables was assessed calculating variation inflation factors (VIF) (command'vif' in R package car), which determined highly correlated variables (VIF < 5) (Zuur et al. 2010). The variables entered in Generalized Linear Models were plant cover, $\mathrm{pH}$, conductivity (nutrient availability) and bog water level. The best fitting models were selected using stepwise backward selection by Akaike information criterion (AIC). If overdispersion was detected, I corrected the standard errors using a quasi-Poisson GLM model and pseudo R2 (Zuur et al. 2009).

Principal component analysis (PCA) was used to ordinate the relationship among species and their habitats (Jongman et al. 1995). The acronyms of scientific species names of ground beetles in the ordination use the first three letters of the genus and species (S 3). Species in which less five individuals were found were omitted from ordination analyses. The carabid beetle numbers were $\log 10(n+1)$ transformed since many species had a zero-values.

The effects of the measured abiotic factors on species distribution were analysed using canonical correspondence analysis $(\mathrm{CCA})$. The data were $\log _{10}(\mathrm{n}+1)$ transformed to reduce the effects of the most abundant carabid species, and species occurring at only one habitat were excluded (Lepš and Šmilauer 2003).
For the statistical analyses software R 3.4 .3 was used (R Core Team 2017).

\section{Results}

Ground beetle species richness, diversity and abundance

A total of 9,177 specimens belonging to 52 carabid beetle species were found. The ground beetle species richness ranged from 9 in hollows to 31 in pine bogs (Fig. 1, Table 1). Species richness (ANOVA, $\mathrm{F}=9.8, P=0.001$ ) and abundance (Kruskal-Wallis test, $\mathrm{H}=22.65, P=0.003$ ) differed significantly among the assemblages of six habitats. The mean abundance of ground beetles and species richness revealed clear assemblage patterns in different sites. The lowest species richness and abundance were recorded in the hollows, whereas the highest species richness and abundance were in pine bogs (Fig. 1).

The non-parametric species richness estimators of Chao 1 and Jackknife 1 provided average expected species richness that are close to the actual overall richness recorded in the study area (Table 1). The estimators showed that the number of carabid species in the different habitats was $10-54$ species suggesting that the observed total of 9-31 species represented $59.25 \%$ to $90.0 \%$ of the actual species richness (Table 1 ).

Agonum ericeti (64.55\%-88.46\%), Pterostichus diligens $(6.13 \%-18.93 \%)$ were the most abundant species in all habitats (Table S3). More than a half $(40.90 \%-62.50 \%)$ of species in assemblages is represented by singletons or doubletons.

Shannon index value (ANOVA, $\mathrm{F}=10.44, P<0.001$ ) differed significantly among the assemblages of six habitats. Diversity measures indicate a higher values in the sites near to the edge of the peat bog such as lagg zone $\left(\mathrm{H}^{\prime}=1.334\right)$ and pine forests $\left(H^{\prime}=1.157\right)$ compared to the habitats on the dome $\left(\mathrm{H}^{\prime}=0.478\right)$ and open bogs $\left(\mathrm{H}^{\prime}=0.770\right)($ Table 1$)$.
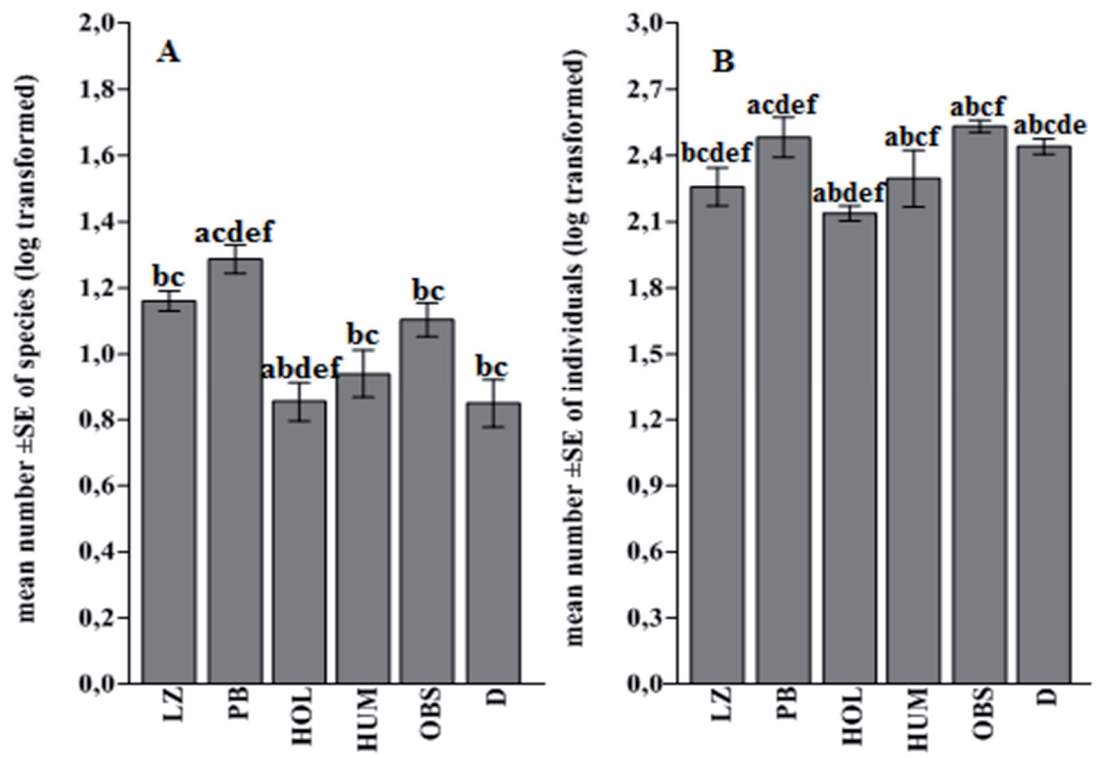

Figure 1. (A) Species richness and (B) abundance in carabid beetle assemblages of six peat bog habitats: (a) LZ - lagg zone, (b) PB - pine bog, (c) HOL - hollows, (d) HUM - hummocks, (e) OBS - open bog, (f) D - dome. Differences among habitats were tested using the Kruskal-Wallis test. Different letters $(\mathrm{a}, \mathrm{b}$, $c, d, e, f)$ indicate significant differences (post-hoc Dunn's test; $\mathrm{P}<0.05)$. 
Table 1. Overview of the parameters of carabid beetle assemblages. LZ - lagg zone, PB - pine bog, HOL - hollows, HUM - hummocks, OBS - open bog, D - dome.

\begin{tabular}{|c|c|c|c|c|c|c|}
\hline \multirow{2}{*}{ Parameters } & \multicolumn{6}{|c|}{ Habitats } \\
\hline & LZ & $\mathrm{PB}$ & $\mathrm{HOL}$ & HUM & OBS & $\mathrm{D}$ \\
\hline Number of observed species & 22 & 31 & 9 & 16 & 23 & 16 \\
\hline Chao 1 & 31.2 & 50.4 & 10.0 & 23.0 & 45.0 & 26.5 \\
\hline Estimate standard error & 7.06 & 12.6 & 1.8 & 6.6 & 16.7 & 17.4 \\
\hline Jackknife 1 & 32.0 & 48.0 & 12.0 & 22.0 & 37.0 & 27.4 \\
\hline Estimate standard error & 4.5 & 5.8 & 2.4 & 4.0 & 5.3 & 4.7 \\
\hline Shannon index (H') & 1.334 & 1.357 & 0.937 & 0.793 & 0.770 & 0.478 \\
\hline Shannon index standard error & 0.11 & 0.12 & 0.09 & 0.15 & 0.04 & 0.06 \\
\hline
\end{tabular}

Table 2. Relationship of total carabid beetle species richness abundance and diversity to environmental factors with generalized linear model multiple regression. Significance codes: ${ }^{* * *} \mathrm{p} \leq 0.0001,{ }^{*} \mathrm{p} \leq 0.001,{ }^{*} \mathrm{p} \leq 0.05$.

\begin{tabular}{|c|c|c|c|c|}
\hline Parameters & Estimate & SE & $\mathrm{t}$-value & $P$ \\
\hline \multicolumn{5}{|c|}{ species richness (Poisson GLM; Pseudo $\mathrm{R}^{2}=0.625$ ) } \\
\hline intercept & 2.181 & 0.535 & 4.078 & $* * *$ \\
\hline total plant cover & 0.012 & 0.002 & 4.980 & $* * *$ \\
\hline $\mathrm{pH}$ & 0.340 & 0.137 & 2.474 & * \\
\hline conductivity & -0.001 & 0.009 & -0.208 & n.s \\
\hline water level & -0.010 & 0.006 & -1.769 & n.s \\
\hline \multicolumn{5}{|c|}{ abundance (Quasi-GLM; Pseudo R²= 0.528) } \\
\hline intercept & 5.426 & 0.703 & 7.712 & $* * *$ \\
\hline total plant cover & 0.011 & 0.003 & 3.425 & ** \\
\hline $\mathrm{pH}$ & 0.399 & 0.179 & 2.226 & * \\
\hline conductivity & -0.024 & 0.011 & -2.063 & * \\
\hline water level & 0.062 & 0.032 & 3.588 & n.s \\
\hline \multicolumn{5}{|c|}{ Shannon-diversity (Quasi-GLM; Pseudo R²=0.613) } \\
\hline intercept & 0.874 & 0.363 & 2.404 & $*$ \\
\hline total plant cover & 0.006 & 0.002 & 2.242 & * \\
\hline $\mathrm{pH}$ & 0.181 & 0.140 & 1.292 & n.s \\
\hline conductivity & 0.008 & 0.009 & 0.890 & n.s \\
\hline water level & -0.022 & 0.061 & -3.242 & $* *$ \\
\hline
\end{tabular}

Environmental variables driving the ground beetle diversity pattern

Among the variables included in the GLM analyses, plant cover $(P<0.001)$, and $\mathrm{pH}(P<0.001)$ were significantly positively correlated with carabid beetle species richness and emerged as the most important predictors in this model. The significant predictor variables for ground beetle abundance were plant cover $(P<0.001)$, conductivity $(P<0.01)$, and $\mathrm{pH}(P<0.01)$. Besides, plant cover and $\mathrm{pH}$ showed a positive effect, whereas, nutrient availability (conductivity) had a negative effect. Plant cover $(P<0.01)$, which had a positive effect and bog water level $(P<0.001)$, which negatively related with the Shannon-diversity (Table 2).

Environmental variables influencing ground beetle assemblage structure

PCA analyses revealed that carabid species were correlated with distinct sites, which indicates environmental heterogeneity (Fig. 2). The two first PCA axes interpreted $75.25 \%$ and $10.22 \%$ of the variation, and they gave a cumulative percentage of variance explained of $85.47 \%$ by them. Many species not associated with peat bogs, including Carabus hortensis, Poecilus cupreus, P. versicolor, Agonum sexpunctatum and Epaphius rivularis were correlated with the lagg zone. Habitat bog specialists, such as Agonum ericeti, Pterostichus diligens, P. rhaeticus, and Bembidion humerale, were correlated with open treeless spaces on the slope of bog (OBS, HUM). Hygrophilous species Carabus clathratus was correlated with hollows. Correlation for the pine bog was shown for some forest species such as Cychrus caraboides, Oxypselaphus obscurus, Pterostichus niger, and P. oblongopunctatus. Carabus nitens and Dicheirotrichus cognatus seemed to be associated with treeless and the less wet sites on the bog dome.

The CCA analyses indicated that the environmental variables explaned for $73.00 \%$ of the total variance. On the other hand, the Monte Carlo permutation test $(P<0.01)$ revealed that plant cover $($ F-ratio $=2.75, P=0.03)$, water level (F-ratio $=2.75, P=0.02$ ), and nutrient availability (conductivity) (F-ratio $=1.89, P=0.02)$ were significant in interpreting carabid beetle heterogeneity.

Poecilus cupreus, P. versicolor, Notiophilus palustris, Carabus hortensis, Epaphius secalis, and Oxypselaphus obscurus showed a relationship with conductivity gradient. 
Carabus clathratus corresponded the gradient of water level. Some of the species associated with vascular plant cover were Carabus nitens, Bradycellus ruficollis, Cychrus caraboides, Pterostichus niger and P. oblongopunctatus. Peat bog specialists, which are plotted in the centre of the ordination diagram, distributed in all habitat types and can be similar in their habitat preferences, being highly abundant. Agonum ericeti, Bembidion humerale, Pterostichus diligens and P. rhaeticus among them (Fig. 3). It supports suggestion about conservation and almost intact state of Belarusian peat bogs.

\section{Discussion}

The present study of carabid beetles provides a background for identifying of the key factors affecting the diversity of species associated with Sphagnum habitats within peat bogs. The largely intact and near pristine large Belarusian peat bogs are a valuable resource for undertaking such studies, whereas in most other countries it is not possible due to much higher levels of anthropogenic modification historically. Furthermore, these sorts of investigations can provide a monitoring baseline informing a more scientific approach to the planning and management of a system of protected areas around European wetlands.

\section{Ground beetle species richness, diversity and abundance}

As with other similar studies, the species richness and diversity of ground beetles were found to be low (Spitzer et al. 1999, Främbs et al. 2002, Mossakowski et al. 2003, Dapkus and Tamutis 2008, Spungis 2008). There are several previous studies which were conducted on two main habitat types: open bog and its edge (Spitzer et al. 1999, Dapkus and Tamutis 2008). The results of this study demonstrated a number of the main trends associated with the spatial distribution of ground beetles in a wider range of habitats in an area of large and almost intact peatlands. In that work a high abundance of a few carabid species was found in six of the peat bog habitats; and these were coincident with those species which are most adapted to the extreme environmental conditions of bogs (Spitzer and Danks 2006) in Central-Eastern Europe. Higher diversity measures in assemblages in the lagg zone and pine forest habitats near to the edge of the peat bogs tend to indicate the presence of species from adjacent ecosystems. Hence there is usually a trend of higher species richness, diversity and abundance of carabid beetles on edges or adjacent habitats compared to the open bog (Spitzer et al. 1999, Dapkus and Tamutis 2008). This may be attributable to edge effects. This pattern has also been documented not only for carabid beetles, but also for other invertebrates, e.g. planthoppers and leafhoppers (Sushko 2016b).
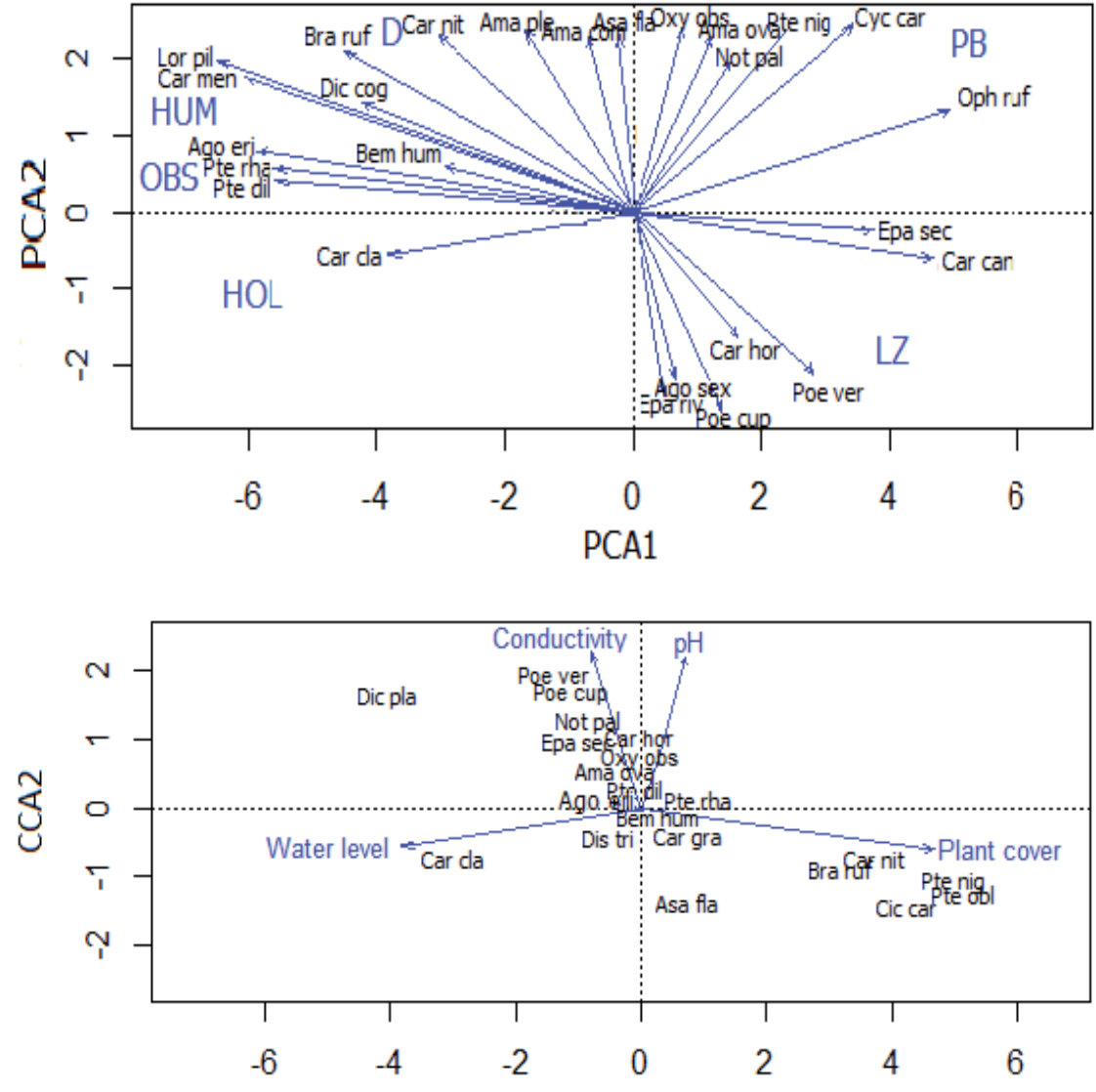

CCA1
Figure 2. Figure 2. - PCAordination diagram of the carabid beetle assemblages of six peat bog habitats: LZ - lagg zone, $\mathrm{PB}$ - pine bog, HOL hollows, HUM - hummocks, OBS - open bog, D - dome. (Species abbreviations are given in Table S3).

Figure 3. CCA-ordination diagram of the carabid beetle assemblages of six peat bog habitats: LZ - lagg zone, PB - pine bog, HOL - hollows, HUM - hummocks, OBS open bog, D - dome. (Species abbreviations are given in Table S3). 
Environmental variables driving the ground beetle diversity pattern

The results of this study showed that diversity of carabid assemblages varied from the lagg to the dome and this trend is primarily related to habitat heterogeneity and environmental gradients. Among the abiotic factors limiting peat bog plant diversity were; poor mineral nutrition, strong acidity of the Sphagnum cover and high water level (Wieder et al. 2006, Rydin and Jeglum 2006). The controlling variables most influencing carabid species richness and abundance were mineral nutrition and $\mathrm{pH}$, but moisture regime was not found to be significant. The bog water level would appear then not an important variable affecting the species richness and abundance of carabid beetles in a Sphagnum carpet. It can probably be explained by the fact that several of the most abundant species that predominate in all ground beetle assemblages are hydrophilic peat bog specialists, such as Agonum ericeti, Pterostichus diligens, and P. rhaeticus. These species are known to prefer wet peat habitats above other habitat types (Aleksandrowicz 2014). On the other hand, the Sphagnum cover is filled with water through precipitation. In rainless periods when Sphagnum loses water even in the wettest places, ground beetles can actively move around the peat bog habitats. But still it cannot be argued that humidity is not an important factor for ground beetles, as some species were sensitive to the bog water level.

One particularly influential biotic variable was found to be plant cover. The plant cover varies smoothly along the gradient from the edge to the dome, and perhaps this is the factor for maintaining the micro-climatic conditions that influence the life of animals, plants, and microorganisms close to the ground in peat bogs, by helping to control amongst other micro-climatic factors, the pronounced amplitude of daily temperatures and insolation (Spitzer and Danks 2006).

\section{Environmental variables influencing ground beetle assemblage structure}

The results of this study demonstrate a differential use of resources and microhabitats by the different carabid species in peat bog habitats; however, some similarities in the patterns of their distribution also have been found. For example open treeless space provides a more suitable habitat for specialised peat bog species. Among these species are Agonum ericeti, Pterostichus diligens, P. rhaeticus, and Bembidion humerale (Främbs et al. 2002, Mossakowski et al. 2003, Aleksandrowicz 2014). Such species are associated with milder microclimatic conditions, due to the local warming associated with higher levels of insolation e.g. (Mossakowski 1970, Spitzer and Danks 2006). On the other hand, the pine bog appears more appropriate for certain forest species with a preference for more shaded habitats. By contrast, the lagg zone, which was characterised by highest nutrient availability (indicated by highest conductivity levels), is most suitable for many eurytopic species, the majority of which are probably migrants. Among these species Carabus hortensis, Poecilus cupreus, P. versicolor, Agonum sexpunctatum and Epaphius rivularis are usually found in open habitats (e.g., meadows, cultural fields, etc.) having different hygropreferences (Aleksandrowicz 2014). The inhabitants of the European heath Carabus nitens (Coleoptera Poloniae 2017) and Dicheirotrichus cognatus (Database of Insects and their food 2017) seemed to be associated with treeless and the less wet sites on the bog dome.

The work here emphasises that the composition of carabids can be affected by different environmental variables, such as plant cover, nutrient availability and also water level for some species. Sphagnum probably doesn't offer suitable conditions and resources for non specialists, such as many forest and other wetland dwellers. This may also possibly reflect unfavorable $\mathrm{pH}$ values, as peat bogs are highly acidic (Rydin and Jeglum 2006). Whereas specialised ground beetles appear not to be as sensitive to the $\mathrm{pH}$ gradient, and such acidic locations may provide optimal conditions for peat bog ground beetles, which prefer low $\mathrm{pH}$ values (Mossakowski 1970, Paje and Mossakowski 1984).

The results reveal environmental heterogeneity of habitats; thus for example the carabid assemblage structure in lagg areas were probably driven by electrical conductivity, while vascular plant cover were key factors in the slope and dome habitats. Whereas, water level appears to be the most important control for the hollows. At the same time, specialised peat bog species showed low sensitivity to the gradient of the analysed variables, which demonstrates their likely high level of adaptation to the extreme conditions of peat bogs.

\section{Peat bogs as important strongholds for the survival of the rare and protected carabid species}

The isolated ancient Central European peat bog ecosystems could be classified as paleorefugia and as suitable habitats of some formerly tundra and taiga inhabitants, that live here since the early Holocene (Spitzer and Danks 2006). Large peat bogs preserved in Belarus are protected areas and favor the conservation of insect diversity of European wetlands. Ground beetles are worldwide known and one of the most studied taxon for conservation research and for monitoring studies. The stenotopic peat bog ground beetle Agonum ericeti is among them (Mossakowski 1970), and while the potential of Agonum ericeti as target species for monitoring peat bogs is high, in most Central European countries its number is reduced as a result of the degradation and fragmentation of these habitat types (Drees at al. 2007). Also, three recorded species are listed in the Belarusian Red Book: Carabus clathratus (VU), C. menetriesi (VU), and C. nitens (VU). Additionally, a rare and circumpolar Wide-Boreal species Blethisa multipunctata was found. A general recommendation for the conservation of rare, protected, and specialised peat bog ground beetles is to preserve the plant communities, by avoiding disturbances to the regional water table (Spitzer and Danks 2006).

\section{Conclusions}

The results of this study provide an improved understanding of the habitat distribution of carabids in relation to 
the key environmental factors that appear to determine their composition pattern. The main environmental variables limiting ground beetle diversity and species composition were found to be abiotic factors such as $\mathrm{pH}$, bog water level and the conductivity of the Sphagnum mat water, as well as vascular plant cover. In addition, the investigation of the habitat variables driving those biodiversity patterns is important in establishing proper guidelines for the conservation of these unique peat bog fauna.

This carabid investigation also presents a basis for identifying centers of biodiversity within the protected areas of European wetlands. Such researches can afford a better scientific ground by which to plan and manage a system of protected areas around these centers in accordance with the convention on biological diversity (Glowka et al.1994). Peat bogs Yelnia and Moh, among of the largest and least anthropogenically modified European wetlands, were found to be the repository of many of the cold adapted boreal beetles in the temperate zone of Europe, and hence is an especially important site in the context of global warming.

Acknowledgments: The author is thankful to three anonymous reviewers and J. Coll (National University of Ireland, Maynooth, Ireland) for linguistic help.

\section{References}

Aleksandrowicz, O. 2014. Ground Beetles (Coleoptera, Carabidae) of the West Part of Russian Plane. Fauna, Zoogeography, Ecology, Genesis of Fauna. Lambert Academic Publishing, Saarbrücken.

Bambalov, N.N. and V.A. Rakovich. 2005. Mires in the Biosphere. Belorusskaja kniga, Minsk.

Bragg, O. and R. Lindsay (eds.) 2003. Strategy and Action Plan for Mire and Peatland Conservation in Central Europe. Wetlands International, Wageningen.

Brown, D. 1954. Methods of Surveying and Measuring Vegetation. Commonwealth Bureau of Pastures and Field Crops, Hurley, Berkshire.

Chao, A. 1987. Estimating the population size for capture-recapture data with unequal catchability. Biometrics 43:783-791.

Chao, A., K.H. Ma, T.C. Hsieh, and C.H. Chiu. 2015. Online Program Spade R (Species-richness Prediction and Diversity Estimation in R). Program and User's Guide. Available from: http://chao. stat.nthu.edu.tw/wordpress [Accessed 5 August 2018]

Coleoptera Poloniae. Available from: http://www.coleoptera.ksib.pl. [Accessed 30 Oct 2017]

Coll, J., D. Bourke, M. Sheehy Skeffington, M. Gormally and J. Sweeney. 2014. Projected loss of active blanket bogs in Ireland. Clim. Res. 59:103-115.

Coll, J., D. Bourke, R.L. Hodd, M. Sheehy Skeffington, M. Gormally and J. Sweeney. 2016. Projected climate change impacts on upland heaths in Ireland. Clim. Res. 69:177-191.

Database of Insects and their Food Plants. Available from: http:/ www.brc.ac.uk. [Accessed 30 Oct 2017].

Dapkus, D. and V. Tamutis. 2008. Assemblages of beetles (Coleoptera) in a peatbog and surrounding pine forest. Baltic $J$. Coleopterol. 8(1):31-40.
Drees, K., K. Matern, R. Vermeulen and T. Assmann. 2007. The influence of habitat quality on populations: a plea for an amended approach in the conservation of Agonum ericeti. Baltic J. Coleopterol. 7(1):1-8.

Främbs, H., W. Dormann and D. Mossakowski. 2002. Spatial distribution of carabid beetles on Zehlau bog. Baltic J. Coleopterol. 2(1):7-15.

Freude, H., K. Harde and G.A. Lohse. 2004. Die Käfer Mitteleuropas. Band 2. Adephaga 1. Carabidae (Laufkäfer). Spektrum-Verlag, Heidelberg-Berlin.

Glowka, L., F. Burnhenne-Guilmin, H. Synge, J.A. Mc Neely and L. Gundling. 1994. A Guide to the Convention on Biological Diversity. IUCN, Gland.

Hammer, Ø., D.A.T. Harpe and R.D. Ryan. 2001. PAST: Paleontological Statistics Software Package for Education and Data Analysis. Palaeontol. Electrónica 4(1):9.

Hůrka, K. 1996. Carabidae of the Czech and Slovak Republics. Kabourek, Zlín.

Jongman, R.H.G., C.J.F. ter Braak and O.F.R. van Tongeren. 1995. Data Analysis in Community and Landscape Ecology. Cambridge University Press, New York.

Lepš, J. and P. Šmilauer. 2003. Multivariate Analysis of Ecological Data Using CANOCO. Cambridge University Press, New York.

Maavara, V. 1957. The entomofauna Endla peat bog. Eestj NVS Teeaduste Akadeemia Juures asuva loodusuurijate seeltsi. 50:119-140.

Magurran, A.E. 2004. Measuring Biological Diversity. Blackwell Science, Oxford.

Mossakowski, D. 1970. Das Hochmoor-Ökoareal von Agonum ericeti (Panz.) (Coleoptera, Carabidae) an die Frage der Hochmoorbindung. Faun. Ökol. Mitt. 3:378-392.

Mossakowski, D., H. Frambs and W. Lakomy. 2003. The Carabid and Staphylinid fauna of raised bogs. A comparison of Northwest Germany and the Baltic region. Baltic J. Coleopterol. 3(2):137144.

Paje, F. and D. Mossakowski. 1984. pH-preferences and habitat selection in carabid beetles. Oecologia 64:41-46.

Peus, F. 1928. Beitrage zur Kenntnis der Tierwelt nord west deutscher Hochmoore. Eine okologische Studie. Insecten, Spinnentiere, Wirbeltiere. Z. Morphol. Oekol. Tiere. 12:533-683.

R Core Team. 2017. R: A Language and Environment for Statistical Computing. RStudio, Inc., Boston, MA.

Rydin, H. and J.K. Jeglum. 2006. The Biology of Peatlands. Oxford University Press, Oxford.

Siegel, S. and N.J.Jr. Castellan. 1988. Nonparametric Statistics for the Behavioral Sciences. 2nd ed. McGraw-Hill, New York.

Spitzer, K., A.Bezděk and J. Jarǒs. 1999. Ecological succession of a relict Central European peat bog and variability of its insect biodiversity. J. Insect Conserv. 3:97-106.

Spitzer, K. and H.V. Danks. 2006. Insect biodiversity of boreal peat bogs. Annu. Rev. Entomol. 51:137-161.

Spungis, V. 2008. Fauna and Ecology of Terrestrial Invertebrates in Raised Bog in Latvia. Latvias Entomology Bedriba, Riga.

Sushko, G. 2016a. Species composition and diversity of the true bugs (Hemiptera, Heteroptera) of a raised bog in Belarus. Wetlands 36(6):1025-1032.

Sushko, G. 2016b. Succession changes in diversity and assemblages composition of planthoppers and leafhoppers in natural ancient peat bogs in Belarus. Biodivers. Conserv. 25(14):2947-2963. 
Wieder, R.K. and D.H. Vitt (eds). 2006. Boreal Peatland Ecosystems. Ecological Studies, Vol. 188. Springer-Verlag, Berlin, Heidelberg.

Zuur, A.F., I.N. Ieno, N.J. Walker, A.A. Saveliev and G.M. Smith. 2009. Mixed Effects Models and Extensions in Ecology with R. Springer, Berlin.

Zuur, A.F., E.N. Ieno and C.S. Elphick. 2010. A protocol for data exploration to avoid common statistical problems. Methods. Ecol. Evol. 1:3-14.

Received August 31, 2018 Revised November 30, 2018, February 11, 2019 Accepted February 16, 2019

\section{Supplementary material}

Table S1. Study site characteristics.

Table S2. Mean values of environmental variables in the six peat bog habitats.

Table S3. Carabid beetle assemblages of six main habitats in the peat bogs: lagg zone, pine bog, hollows, hummock, open bog and dome.

The appendix may be downloaded from www.akademiai. com. 